\title{
Morphometric and Radiomorphometric Study of the Correlation Between the Foramen Magnum Region and the Anterior and Posterolateral Approaches to Ventral Intradural Lesions
}

\author{
Sabino LUZZI ${ }^{1,2,3}$, Mattia Del MAESTRO ${ }^{3,4}$, Angela ELIA ${ }^{1}$, Francesca VINCITORIO ${ }^{5}$, Giuseppe Di PERNA ${ }^{5}$, \\ Francesco ZENGA ${ }^{6}$, Diego GARBOSSA ${ }^{5,6}$, Samer K. ELBABAA ${ }^{7}$, Renato GALZIO ${ }^{1,3}$ \\ 'University of Pavia, Diagnostic and Pediatric Sciences, Department of Clinical-Surgical, Neurosurgery Unit, Pavia, Italy \\ "University of Bari "Aldo Moro", PhD Course in Tissues and Organs Transplantation and Cellular Therapies, Department of Emergency and \\ Organ Transplantation, Bari, Italy \\ ${ }^{3}$ Fondazione IRCCS Policlinico San Matteo, Department of Surgical Sciences, Neurosurgery Unit, Pavia, Italy \\ ${ }^{4}$ University of Pavia, PhD School in Experimental Medicine, Department of Clinical-Surgical, Diagnostic and Pediatric Sciences, Pavia, Italy \\ "University of Turin, Department of Neurosciences "Rita Levi Montalcini", Neurosurgery Unit, Turin, Italy \\ ${ }^{6}$ Ospedale Le Molinette, Department of Neuroscience, Neurosurgery Unit, Turin, Italy \\ ${ }^{7}$ Pediatric Neuroscience Center of Excellence, Arnold Palmer Hospital for Children, Orlando, Florida, USA
}

Corresponding author: Sabino LUZZI sabino.luzzi@unipv.it

\section{ABSTRACT}

AIM: To identify the range of dimensional morphometric variability correlated to the basilar and condylar part of the occipital bone, which may affect the choice of approach to ventral intradural foramen magnum (FM) lesions.

MATERIAL and METHODS: In total, 25 dry skulls and 50 head computed tomography (CT) scan results have been assessed in detail, focusing on the FM, occipital condyles, jugular tubercles (JT), and hypoglossal canals (HC). A morphometric analysis has been carried out using linear and angular measurements to estimate the range of the dimensional variability of these structures. Data were presented as mean \pm standard deviation, ranges, and interquartile range on a boxplot. The sagittal intercondylar angle (SICA) and anterior condylar angle (ACA) have been found to be important in estimating the axial orientation of the condyles, whereas the JT-HC interline ratio has indicated the prominence of the tubercles.

RESULTS: The SICA and ACA have exhibited high variability. The average JT-HC interline ratio was 0.8. Wider SICA-ACA and higher JT-HC interline ratio make the posterolateral approach advantageous. An anterior medial or far-medial endoscopic route is indicated in opposite conditions. In this study, two illustrative cases have been reported.

CONCLUSION: A cautious preoperative morphometric evaluation of the FM region must be considered prior to using tailored and safe anterior endoscopic and posterolateral approaches to ventral intradural lesions to identify the advantages of a certain corridor as much as possible, thereby minimizing the risk of complications.

KEYWORDS: Far-lateral approach, Foramen magnum, Jugular tubercle, Occipital condyles, Transclival approach

Sabino LUZZI (1) : 0000-0002-1381-8528

Mattia Del MAESTRO (D): 0000-0002-0521-6519

Angela ELIA
(D) : $0000-0002-0865-774 \mathrm{X}$
Francesca VINCITORIO

Giuseppe Di PERNA

Francesco ZENGA
(1D) : 0000-0001-5646-5120

(D) : 0000-0002-7381-9194

(1) : 0000-0001-5440-3276
Diego GARBOSSA (1D): 0000-0002-2692-7133

Samer K. ELBABAA (D): 0000-0003-1733-1941

Renato GALZIO (1) : 0000-0003-1933-1355 


\section{INTRODUCTION}

$\mathrm{D}$ ue to the extremely complex anatomy, peculiar biomechanics, and deep location of the involved neurovascular structures, the ventral foramen magnum (FM) region is universally considered a formidable area to deal with. Numerous approaches with advantages and disadvantages are commonly used in daily practice to treat extradural and intradural lesions, including those in the anterior border of the FM and lower clivus. Basically, these corridors can be classified into two main groups, namely, the anterior (Figures 1, $2 A-D)(10,13,15,22,33,46,53)$, and posterolateral approaches (Figure 3) $(2,3,17,20,21,25,30,31,40-43,47,54)$. Although the anterior intradural approaches allow direct ventral access to the brainstem and upper cervical cord with zero retraction of the neurovascular structures, they are often too narrow and inadequate for the treatment of lesions with relevant lateral extension. Moreover, the use of such approaches puts patients at high risk for cerebrospinal fluid leaks. Conversely, posterolateral routes offer more surgical freedom but involve working corridors, which are performed across the plane of the lower cranial nerves in most cases. Numerous posterolateral approaches involve the medial transposition of the vertebral artery and encompass drilling of the condyle and the jugular tubercle (JT); therefore, they are associated with the increased risk of mechanical instability or neurovascular iatrogenic injury.

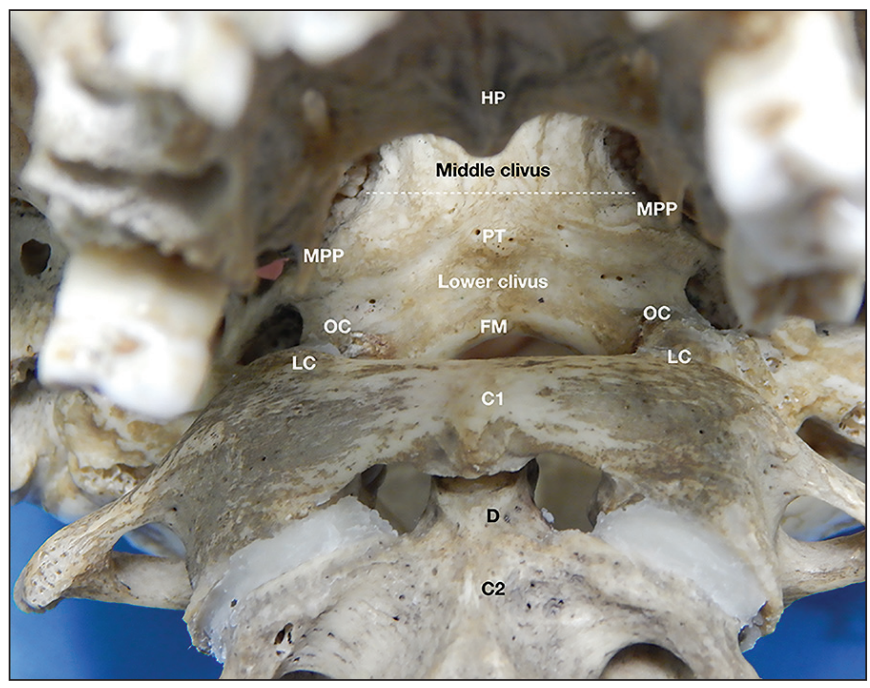

Figure 1: Transoral perspective of the foramen magnum region. The transoral approach allows direct midline access to the foramen magnum region. Mouth-opening capacity, integrity of the temporomandibular joint, macroglossia, dentation, and jaw length may be important limiting factors.

HP: Hard palate; OC: occipital condyle; LC: lateral condyle; FM: foramen magnum; PT: pharyngeal tubercle; C1: atlas; D: dens of the axis; C2: axis; MPP: medial pterygoid plate. The dotted line refers to the inferior clival line and marks the limit between the middle and lower clivus.
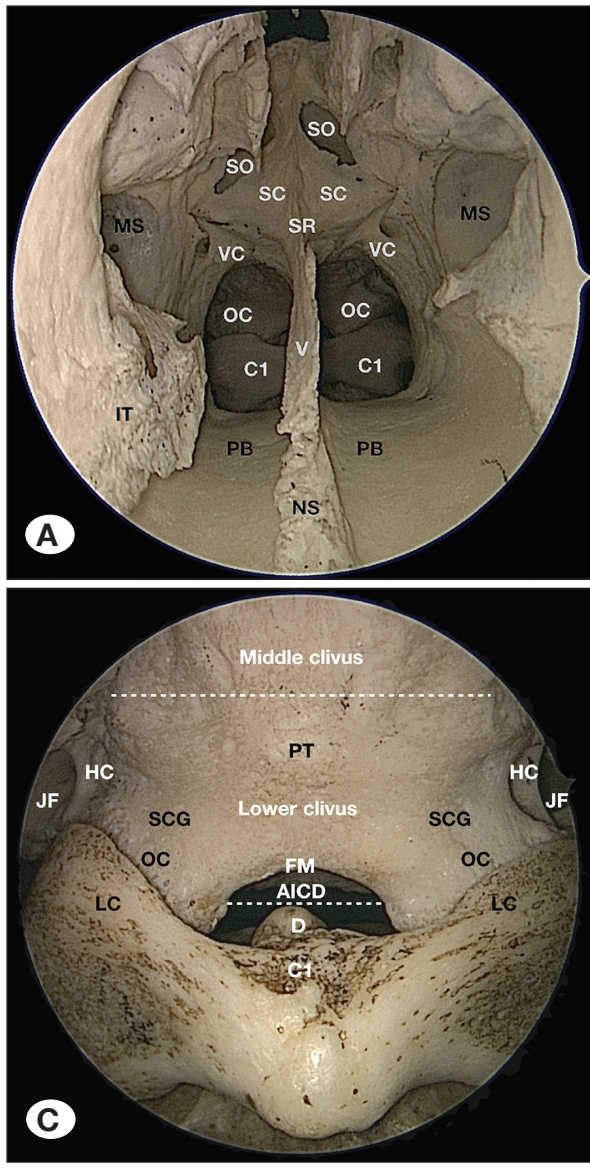

Figure 2: Extended endoscopic endonasal perspective of the medial and far-medial approaches.

A) Nasal stage of the extended endoscopic endonasal medial and far-medial approaches. B) Endoscopic view of the choana and rhinopharynx. C-D) Medial and far-medial vision of the foramen magnum region.

NS: Nasal septum; V: vomer;

SR: sphenoid rostrum; IT: inferior turbinate; PB: palatine bone;

MS: maxillary sinus; SC: sphenoid conchae; SO: sphenoid ostium; VC: vidian canal; OC: occipital condyle; LC: lateral condyle; FM: foramen magnum; D: dens of the axis; $\mathbf{C 1 :}$ atlas; C2: axis; MPP: medial pterygoid plate; HC: hypoglossal canal; PT: pharyngeal tubercle; AICD: anterior intercondylar distance; SCG: supracondylar groove; JF: jugular foramen; PCF: petroclival fissure. 


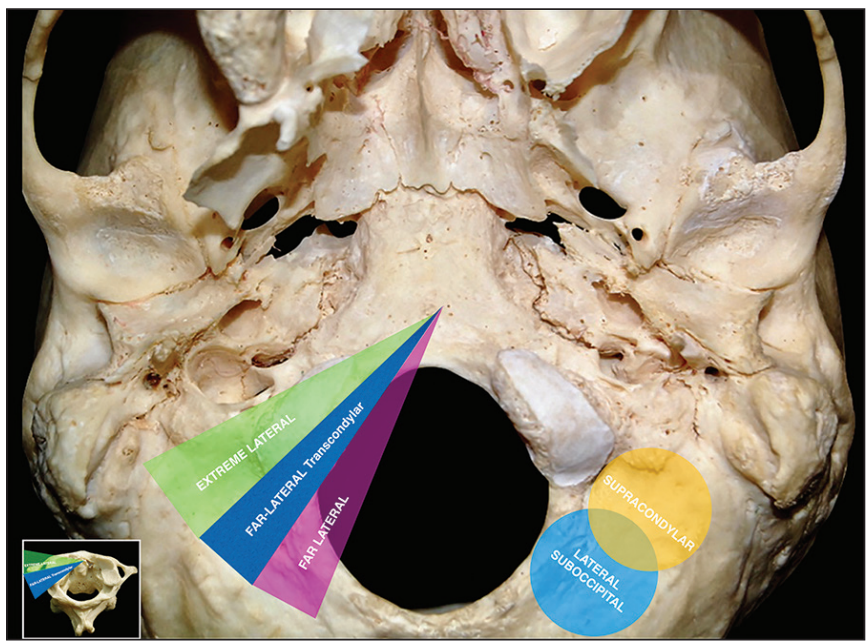

Figure 3: Posterolateral approaches. The lateral suboccipital approach involves craniotomy or craniectomy of the most lateral part of the occipital squama. The far-lateral approach consists of an infero-lateral extension of the lateral suboccipital approach that also involves $\mathrm{C} 1$ hemilaminectomy. The far-lateral transcondylar approach comprehends a partial condilectomy, where the hypoglossal canal is generally preserved, which increases the angle of attack to the target. The supracondylar approach is also referred to as the supracondylar trans-condylar fossa trans-jugular tubercle approach. In this approach, the condyle is completely preserved, and the area of exposure is at the level of the jugular tubercle. The extreme lateral approach is considered a pure lateral route to the lower clivus. Total condylectomy offers a maximal tangential view of the entire basilar part of the occipital bone up to the contralateral petroclival fissure.

The approach of choice to ventral FM pathologies is classically based on lesion-, patient-, and surgery- related factors, and the latter comprehends the confidence and experience the surgeon possesses about specific surgical routes.

An equally paramount aspect regarding the patient and lesion to be treated involves the existence of specific anatomical conditions or variations, which can theoretically make a surgical corridor to ventral FM easier or safer to be performed based on both morphologic and morphometric data.

This study aimed to identify morphometric parameters correlated to the basilar and condylar part of the occipital bone, which are associated with the highest rate of dimensional variability. These may affect the choice of approach to intradural lesions involving the ventral FM and lower clivus.

\section{MATERIAL and METHODS}

This study was approved by the institutional review board of our institution and was reported based on the Strengthening the Reporting of Observational Study in Epidemiology statement (52).

\section{Morphometric and Radiomorphometric Evaluation}

Twenty-five dry skulls of unknown age and gender and 50 adult head computed tomography (CT) scan results have been used to assess the normal dimensional anatomy and the range of anatomical variability of the basilar and condylar parts of the occipital bone. CT scan results were reviewed anonymously, and the need for informed consent was waived. The skulls were measured using a Vernier caliper. CT scans (Toshiba Aquillion ${ }^{\circledR}$ 64, Milwaukee, Wisconsin, the USA) were performed according to the following parameters: $0.5-\mathrm{mm}$ thick slices, $0.3-\mathrm{mm}$ interval, FOV of $240 \mathrm{~mm}$, matrix of 512 $\times 512$, pixel size of $0.46 \mathrm{~mm}, 230 \mathrm{~mA}$, and $120 \mathrm{kV}$. Data have been transferred to a medical imaging work station (Osirix DICOM Viewer ${ }^{\circledR}$, Pixmeo, Bernex, Switzerland) and reviewed with bone setting in sagittal, coronal, axial, and oblique planes according to the different anatomical structures that should be measured. Three-dimensional rendering of the images was also assessed in detail. The FM, condyle, JT, and hypoglossal canal $(\mathrm{HC})$ have been evaluated in detail. All data were reported as mean \pm standard deviation (SD). For paired structures, a t-test between the left- and right side measurements has been performed. A p-value $\leq 0.05$ was considered statistically significant.

\section{Analysis of the Dimensional Variability of the FM Region}

The analysis of the dimensional variability of each morphometric parameter has been carried out by calculating $\mathrm{SD}$, range, and interquartile range reported as a boxplot.

\section{Foramen Magnum}

The longest sagittal axis of the FM has been calculated as the distance between the basion and the opisthion, whereas the largest axial axis coincided with an intercondylar line traced at the level of the posterior tip of each condyle. An FM index dividing the sagittal axis by the axial one has also been obtained. An index $\geq 1.2$ indicated an oval-shaped foramen; otherwise, it was assumed to be round shaped. The FM area has been calculated using the Radinsky (39), and Teixeira methods (50) based on the maximum diameters. These results have been compared with data reported in the literature.

\section{Condyle}

The length and width of the condyles have been measured on the skulls and CT scans, whereas the height has been assessed only on the skulls at the midlevel of each condyle for accuracy purposes. The distances between the anterior condylar tip and the basion (ACT-B) as well as between the anterior condylar tip and the opisthion (ACT-O) have been calculated only on the skulls.

The same procedure has been repeated for the evaluation of the distances between the posterior condylar tip and the basion (PCT-B) and between the posterior condylar tip and the opisthion (PCT-O).

The anterior intercondylar distance (AICD) and the posterior intercondylar distance (PICD) have been calculated at the level of the anterior and the posterior tip of the condyles. The anterior condylar angle (ACA) has been calculated on both the skulls and CT scans at the level of the intersection between the longest axis of each condyle and the midsagittal plane, whereas the sagittal intercondylar angle (SICA) has been evaluated at the intersection between the longest axes of both condyles. 


\section{HC (Anterior Condylar Canal)}

Its inner and outer diameter have been measured on both sides. The distance between the inner orifices has also been calculated and reported as an HC interline. On CT scan, the $\mathrm{HC}$ interline has been evaluated on the coronal plane. In addition, the distance between the posterior tip of the condyle and the midportion of the medial, intermediate, and lateral third of the canal length has been reported as PCT-HC zone 1, PCT-HC zone 2, and PCT-HC zone 3, respectively.

\section{Jugular Tubercle}

The JT interline has been described as the distance between the uppermost part of the tips of the JTs. On CT scan, it has been measured on the coronal plane. The JT interline has been assumed as an indirect estimation of the prominence of the tubercles at the level of the FM area. The JT interline has been correlated to the $\mathrm{HC}$ one and reported as the JT-HC interline ratio, assuming that this parameter can indicate the prominence of the tubercles.

\section{Middle and Lower Clivus}

All morphometric data about the clivus have been obtained from the skulls. The total clival length was reported as the sagittal midline distance between the dorsum sellae of the sphenoid bone and the basion. According to the Funaki's study about the demarcation between the superior, middle, and lower clivus, the length of the middle clivus has been measured as the distance between the superior line located $3.4 \mathrm{~mm}$ below the upper edge of the petrous apex and the inferior line crossing the glossopharyngeal nerve notch of the jugular foramen (15). The number of skulls where a central clival depression could be appreciated has also been reported as the percentage of their overall number.

\section{RESULTS}

\section{Dimensional Anatomy of the FM Region \\ Foramen Magnum}

The longest sagittal axis of the FM measured $35.3 \pm 4 \mathrm{~mm}$, where as the largest axial axis was $30.4 \pm 3 \mathrm{~mm}$ (Figure 4).

The FM index was 1.16, and none of the specimens had an index $\geq 1.2$.

The FM area was $842.3 \mathrm{~mm}^{2}$ with the Radinsky method, and $846.5 \mathrm{~mm}^{2}$ with the Teixeira method.

Table I shows the average FM diameters, index, and area, and their comparison with data reported in or obtained from the literature.

\section{Condyle}

The length, width, and height of the condyles were $23.5 \pm 1$, $11.3 \pm 1$, and $9 \pm 1 \mathrm{~mm}$ on the left side and $23.6 \pm 1,11.7 \pm 1$, and $9.3 \pm 1 \mathrm{~mm}$ on the right side, respectively. No differences were found between the left and right sides. The ACT-B was $10 \pm 2 \mathrm{~mm}$ on both sides. The ACT-O was $38.9 \pm 6$ and 38.7 $\pm 6 \mathrm{~mm}$ on the left and right sides, respectively. The PCT-B measured $28.3 \pm 4$ on the left side and $28 \pm 4 \mathrm{~mm}$ on the right side. The PCT-O was $26.7 \pm 6 \mathrm{~mm}$ on the left side and $26.8 \pm 6$ $\mathrm{mm}$ on the right side. The AICD and PICD were $20 \pm 5$ and 41 $\pm 6 \mathrm{~mm}$, respectively. The ACA was $34.8 \pm 5^{\circ}$ on the left side and $35 \pm 5^{\circ}$ on the right side with a left-right average of 34.9 $\pm 5^{\circ}$. No differences were found between the left and right sides in all condylar parameters. The SICA measured $69.8^{\circ} \pm$ 11 (Figure 5).

Table II shows the summary of the morphometric and radiomorphometric data correlated to the occipital condyles.

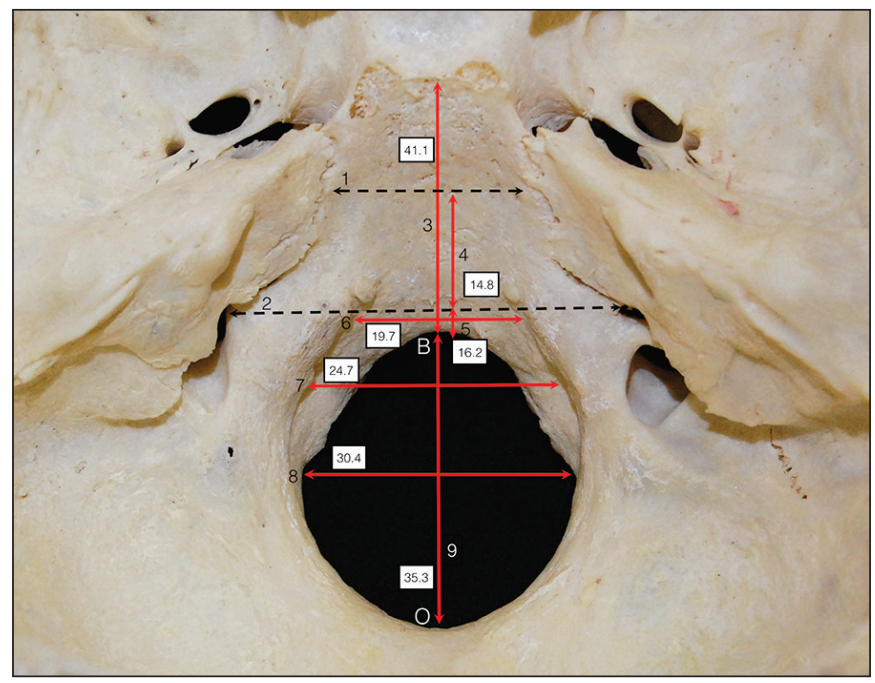

Figure 4: Morphometric analysis of the foramen magnum and the middle and lower clivus. B: basion; O: opisthion; 1: superior clival line; 2: inferior clival line; 3: total clival length; 4: middle clivus length; 5: lower clivus length; 6: jugular tubercle interline; 7: hypoglossal canal interline; 8: axial diameter of the foramen magnum; 9: sagittal diameter of the foramen magnum. All measurements have been reported as average in $\mathrm{mm}$.

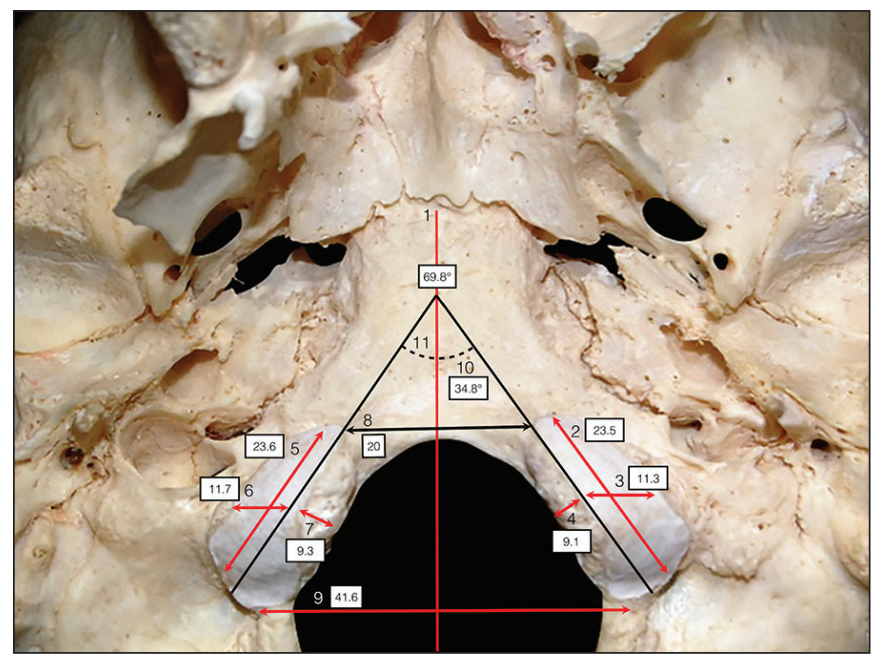

Figure 5: Morphometric analysis of the jugular tubercle. 1: midline; 2-4: length, width, and height of the left occipital condyle; 5-7: length, width, and height of the right occipital condyle; 8: anterior intercondylar distance; 9: posterior intercondylar distance; 10: anterior condylar angle; 11: sagittal intercondylar angle. All measurements have been reported as average in $\mathrm{mm}$. 


\section{HC (Anterior Condylar Canal)}

The inner diameter of the $\mathrm{HC}$ was $4.4 \pm 1 \mathrm{~mm}$ on the left side and $4.5 \pm 1 \mathrm{~mm}$ on the right side, whereas the mean outer diameter was $6.8 \pm 1 \mathrm{~mm}$ on the left side and $7.1 \pm 1 \mathrm{~mm}$ on the right side.The PCT-HC zone 1, PCT-HC zone 2, and PCT$\mathrm{HC}$ zone 3 were $6.8 \pm 1,15.4 \pm 1$, and $17.8 \pm 1 \mathrm{~mm}$ on the left side and $6.7 \pm 1,15.5 \pm 1$, and $17.7 \pm 1 \mathrm{~mm}$ on the right side. No differences were found between the left and right sides for all measurements. The $\mathrm{HC}$ interline measured $24.7 \pm 1 \mathrm{~mm}$ (Figure 6).

Table III shows the morphometric and radiomorphometric data correlated to the $\mathrm{HC}$.

\section{Jugular Tubercle}

The JT interline measured $19.7 \pm 3 \mathrm{~mm}$, and the JT-HC interline ratio was 0.8 .

\section{Middle and Lower Clivus}

The total clival length was $41.1 \pm 4 \mathrm{~mm}$. The lengths of the middle and lower clivus were $14.8 \pm 1$ and $16.2 \pm 0.8 \mathrm{~mm}$, respectively (Figure 4). An evident central clival depression was found in $36 \%$ of the skulls.

Table IV presents the morphometric data of the middle and lower clivus and a comparison with the data reported in the literature.

\section{Dimensional Variability of the Condylar and Basilar Part}

The analysis of SDs, ranges, and interquartile ranges has shown a higher variability in the SICA, ACA, PICD, AICD, ACT-B, ACT-O, PCT-B, PTC-O, and JT interline. The boxplot,

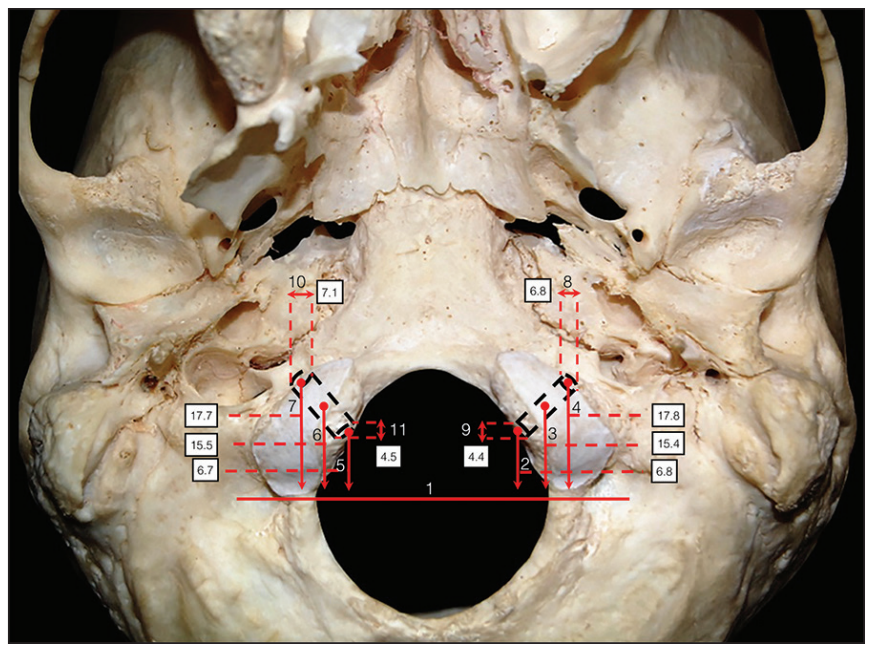

Figure 6: Morphometric analysis of the hypoglossal canal. 1: line marking the posterior limits of the occipital condyles; 2-4: distance between the posterior tip of the condyle and the medial, intermediate, and lateral third lengths of the left canal; 5-7: distance between the posterior tip of the condyle and the medial, intermediate, and lateral third lengths of the right canal; 8-9: outer and inner diameter of the occipital left condyle; 10-11: outer and inner diameter of the occipital right condyle. All measurements have been reported as average in $\mathrm{mm}$.

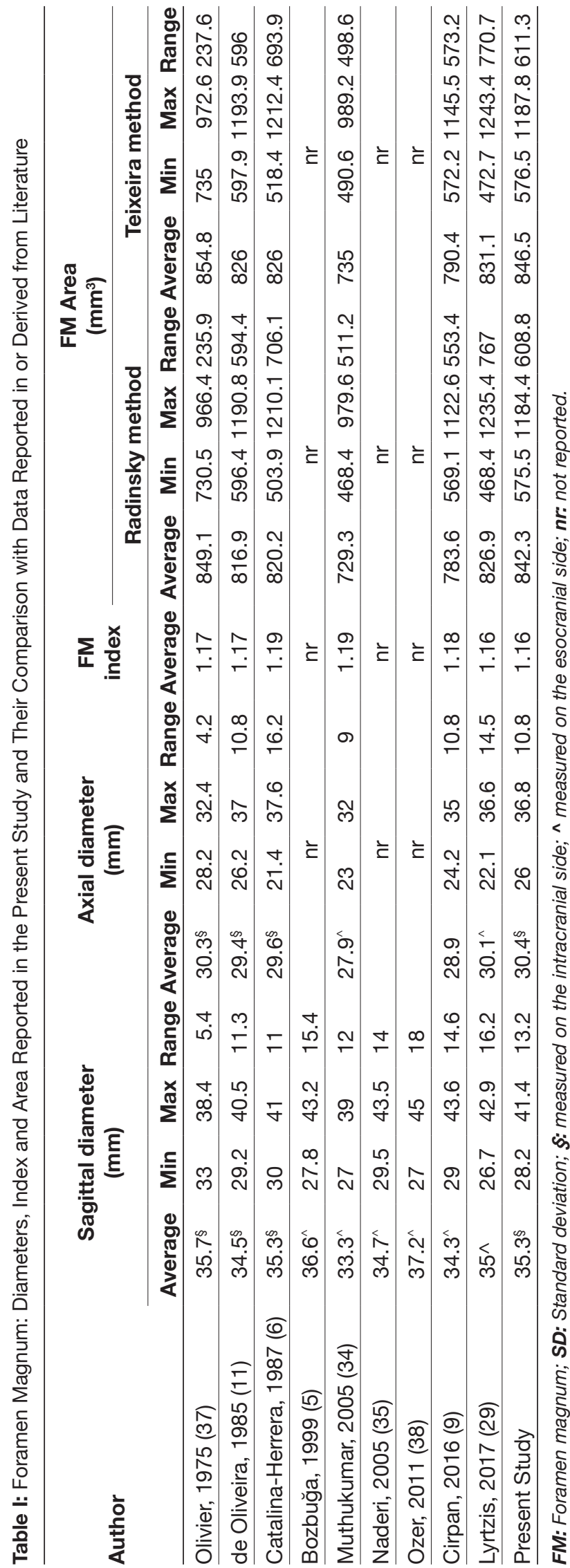




\begin{tabular}{|c|c|c|c|c|c|c|}
\hline \multicolumn{2}{|c|}{ 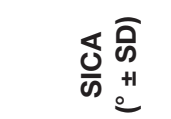 } & $\begin{array}{l}F \\
+1 \\
\infty \\
0 \\
0\end{array}$ & $\begin{array}{l}\stackrel{\sim}{f} \\
\stackrel{f}{*}\end{array}$ & $\begin{array}{l}\stackrel{+}{\sim} \\
\stackrel{\infty}{0}\end{array}$ & 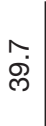 & 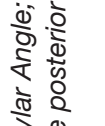 \\
\hline 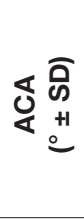 & ـ & $\begin{array}{l}\infty \\
+1 \\
+ \\
\infty \\
\infty \\
\infty \\
+1 \\
\infty \\
\infty \\
\dot{m}\end{array}$ & $\begin{array}{l}\stackrel{\sim}{N} \\
\stackrel{N}{N}\end{array}$ & 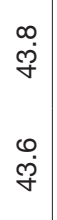 & $\underset{\stackrel{\rho}{\rho}}{\stackrel{\rho}{.}}$ & 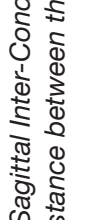 \\
\hline 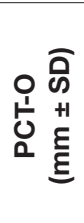 & ــ & 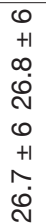 & 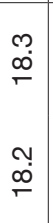 & 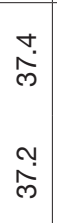 & $\check{\Phi}_{\stackrel{\sigma}{\sigma}}$ & 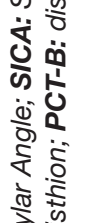 \\
\hline 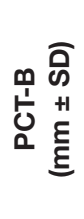 & لـ & $\begin{array}{l}+ \\
+1 \\
\infty \\
\sim \\
+ \\
+1 \\
\infty \\
\infty \\
\infty \\
\sim\end{array}$ & $\begin{array}{l}\stackrel{m}{N} \\
\dot{N} \\
\stackrel{\sim}{N}\end{array}$ & 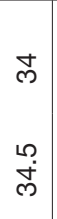 & 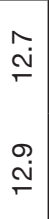 & 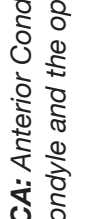 \\
\hline 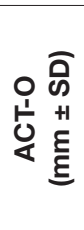 & $\simeq$ & $\begin{array}{l}0 \\
+1 \\
N \\
\infty \\
\infty \\
0 \\
+1 \\
0 \\
\infty \\
\infty \\
\infty\end{array}$ & $\begin{array}{l}\stackrel{N}{N} \\
\text { a }\end{array}$ & f & $\begin{array}{l}\infty \\
\stackrel{\infty}{\sigma}\end{array}$ & 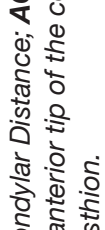 \\
\hline 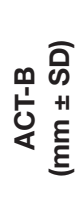 & $\propto$ & $\begin{array}{l}\sim \\
+1 \\
+ \\
+ \\
\sim \\
+1 \\
+ \\
+\end{array}$ & 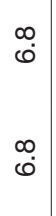 & $\begin{array}{l}\stackrel{\oplus}{\oplus} \\
\stackrel{\sigma}{*}\end{array}$ & $\stackrel{6}{\oplus}$ & 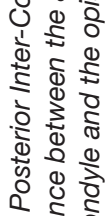 \\
\hline
\end{tabular}

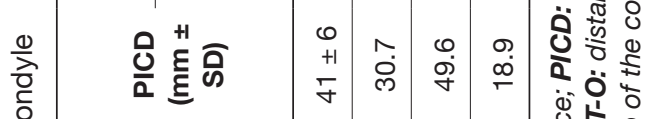

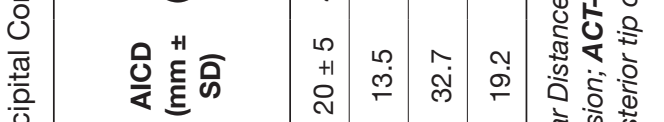

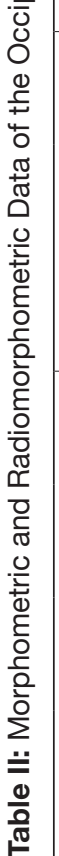

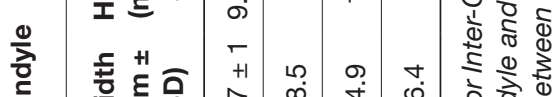

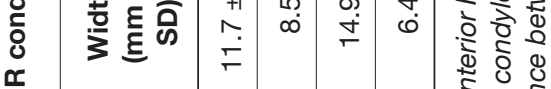

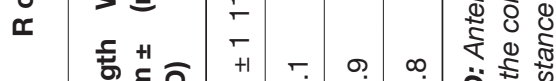

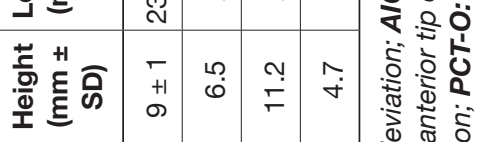

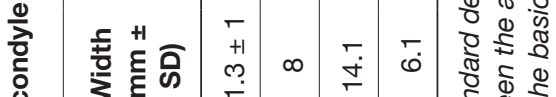

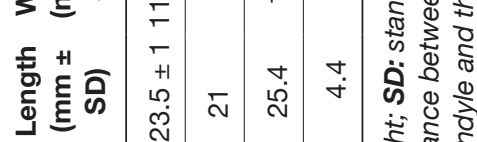

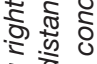

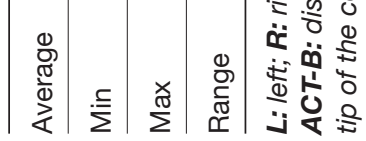

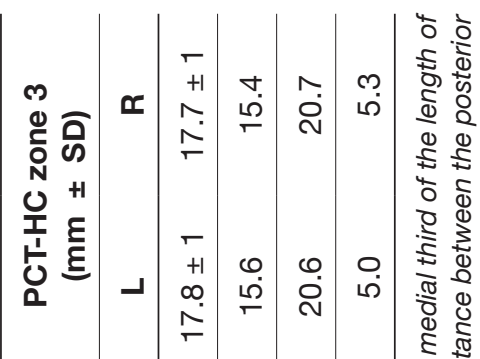

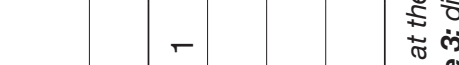

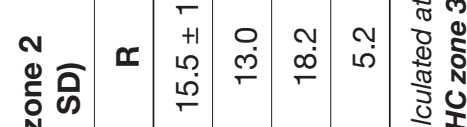

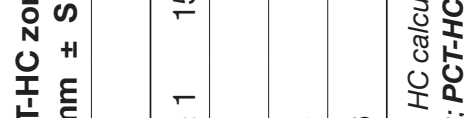

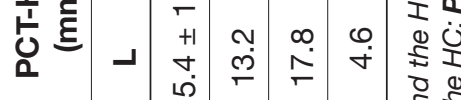

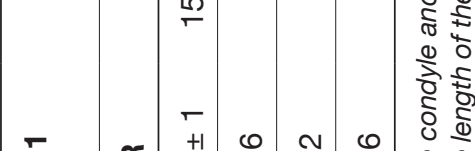

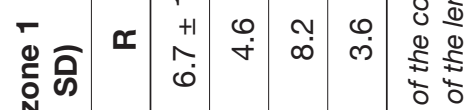

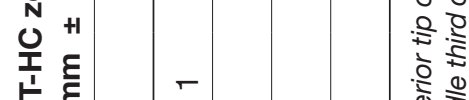

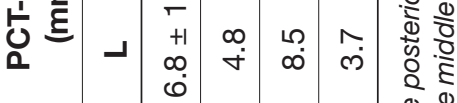

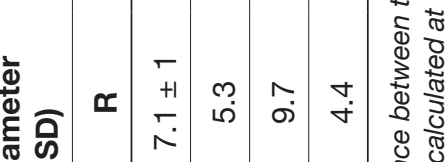

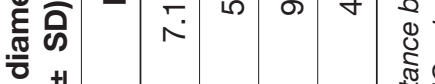

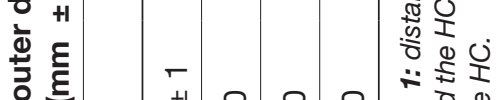

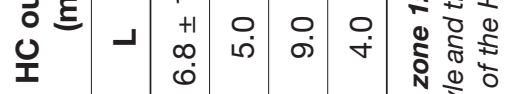

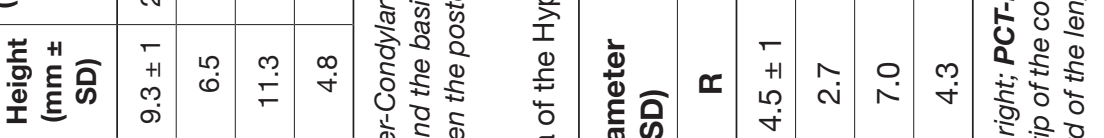

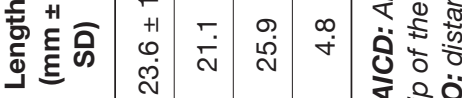

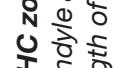

政

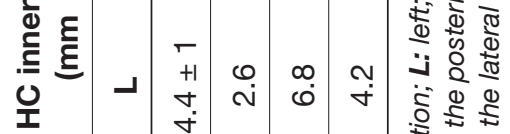

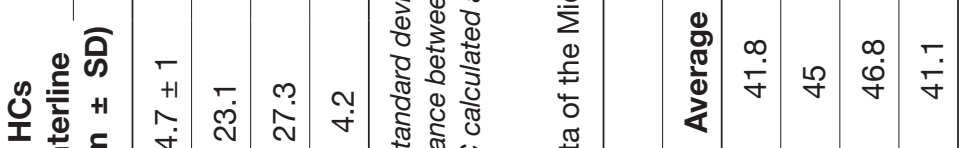

कि

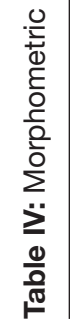

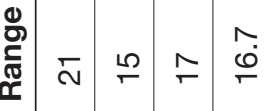

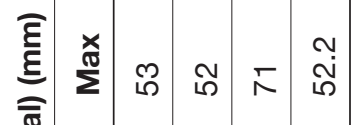

疍

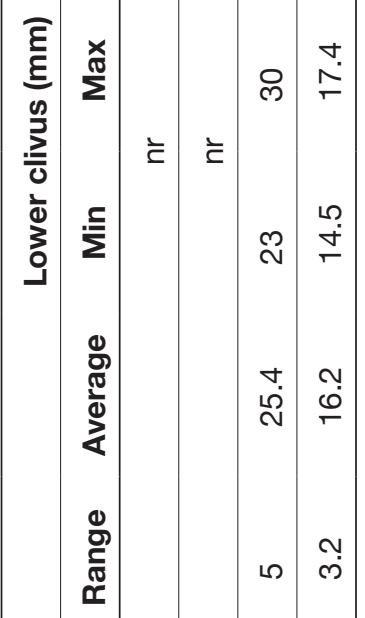

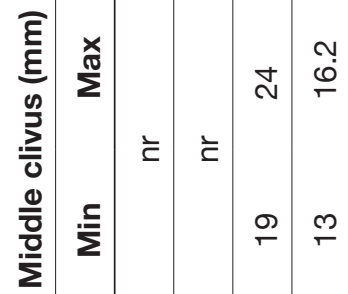

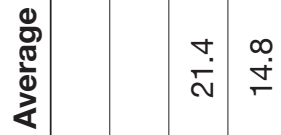

E

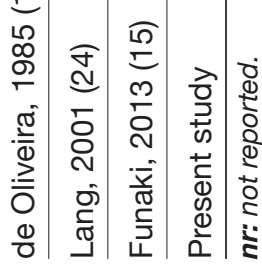


as shown in Figure 7, summarizes the dimensional variability of all the considered morphometric parameters (Figure 7).

\section{Illustrative Cases}

\section{Case 1}

A 38-year-old woman presented with neck pain, tetraparesis, and difficulties in swallowing. Magnetic resonance imaging (MRI) has revealed a midline ventral FM meningioma causing severe cervico-medullary compression. The ACA calculated on preoperative axial CT scan was $75.7^{\circ}$, where as the JT-HC interline ratio was 0.9 . Therefore, a transcranial left far-lateral approach was performed while the patient was in modified park-bench position. The postoperative course was uneventful, and the condition of the patient gradually improved. The tumor histology was grade I meningotheliomatous meningioma, based on the World Health Organization (WHO) classification. A Postoperative MRI after three months has revealed the complete removal of the tumor without complications (Figure $8 \mathrm{~A}-\mathrm{E})$.

\section{Case 2}

A 52-year-old man presented with severe neck pain and ataxia. MRI showed a midline ventral FM meningioma with initial bilateral encasement of the vertebral arteries. The ACA calculated on preoperative axial CT scan was $62.4^{\circ}$, and the JT-HC interline ratio was 0.6. The endoscopic endonasal transclival far-medial intradural approach was used in the tumor. A pedicled nasal septal flap and autologous fascia lata were utilized for dural closure. During the postoperative course, the patient presented with transient dysphagia and completely recovered after six months of follow-up. Histology confirmed a grade I meningotheliomatous meningioma based on the WHO classification. Postoperative CT scan showed the surgical corridor with total removal of the tumor (Figure 9A-E).

\section{DISCUSSION}

The acquisition of greater confidence with the anatomy of the esocranial skull base using the extended endoscopic endonasal approaches (EEEAs), along with the deeper knowledge of the biomechanics of the craniovertebral junction, and the significant improvement of reconstructive techniques have significantly extended the endoscopic option beyond the limits of the extradural compartments. In fact, the use of the EEEAs has recently been proposed for intradural lesions, such as meningiomas involving the ventral $\mathrm{FM}$ and the petroclival region $(4,19,23,53)$, and ventrally located ponto-medullary cavernomas $(12,18,27,36,44,51)$, or even aneurysms of the vertebrobasilar system $(14,26,45,48,49)$. Due to the lower rate of infection or functional complications with the use of EEEAs, such approaches are more preferred than purely microscopic or endoscope-assisted transoral approaches (7). However, at least as far as intradural pathologies affecting the perimedullary cisterns and the brainstem are concerned, EEEAs are still considered pioneering because they still pose a non-negligible rate of complications; thus, transcranial posterolateral approaches are generally preferred. In addition to key factors, such as site, volume, type, and consistency of the lesion; the relationship with the neighboring neurovascular structures; and the surgeon's confidence with a specific corridor, choosing the appropriate approach should also include a cautious evaluation of the posterolateral skull base radiomorphometric parameters. Indeed, in the context of specific patient-related anatomy, a corridor may be safer and more effective than others. This concept is essential in the planning of the approach to extradural FM lesions, but it becomes paramount when dealing with intradural pathologies. The results of the present study confirmed the existence of a dimensional variability within the FM region that mainly involves the axial orientation of the condyle and the prominence of the JT.

Furthermore, the SICA, ACA, PICD, AICD, ACT-B, ACT-O, PCT-B, and PTC-O are all correlated to the orientation of the condyle on the axial plane: the longer the PICD, PCT-B, and PCT-O, the shorter the ACT-B and ACT-O, and the wider the SICA and ACA. Considering these reciprocal relationships, the preoperative evaluation of angular measurements, such as the ACA and SICA, can anticipate the degree of encroachment that the anterior tips of the condyles will have within the anterior medial or far-medial corridor. An ACA and SICA wider than $35^{\circ}$ and $70^{\circ}$, respectively, reduce the surgical freedom of the anterior approaches to the ventral intradural FM lesions and

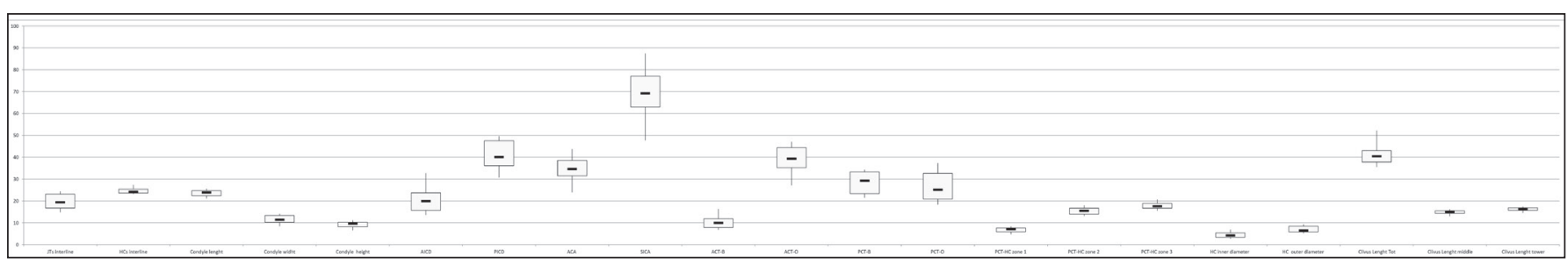

Figure 7: Boxplot reporting the dimensional variability of all the considered morphometric parameters. Solid lines inside the box indicate the median values. JT: Jugular tubercle; HC: hypoglossal canal; AICD: anterior intercondylar distance; PICD: posterior intercondylar distance; ACA: anterior condylar angle; SICA: sagittal intercondylar angle; ACT-B: distance between the anterior condylar tip and the basion; ACT-O: distance between the anterior condylar tip and the opisthion; PCT-B: distance between the posterior condylar tip and the basion; PCT-O: distance between the posterior condylar tip and the opisthion; PCT-HC zone 1: distance between the posterior tip of the condyle and the midportion of the medial third of the hypoglossal canal length; PCT-HC zone 2: distance between the posterior tip of the condyle and the midportion of the intermediate third of the hypoglossal canal length; PCT-HC zone 3: distance between the posterior tip of the condyle and the midportion of the lateral third of the hypoglossal canal length. 

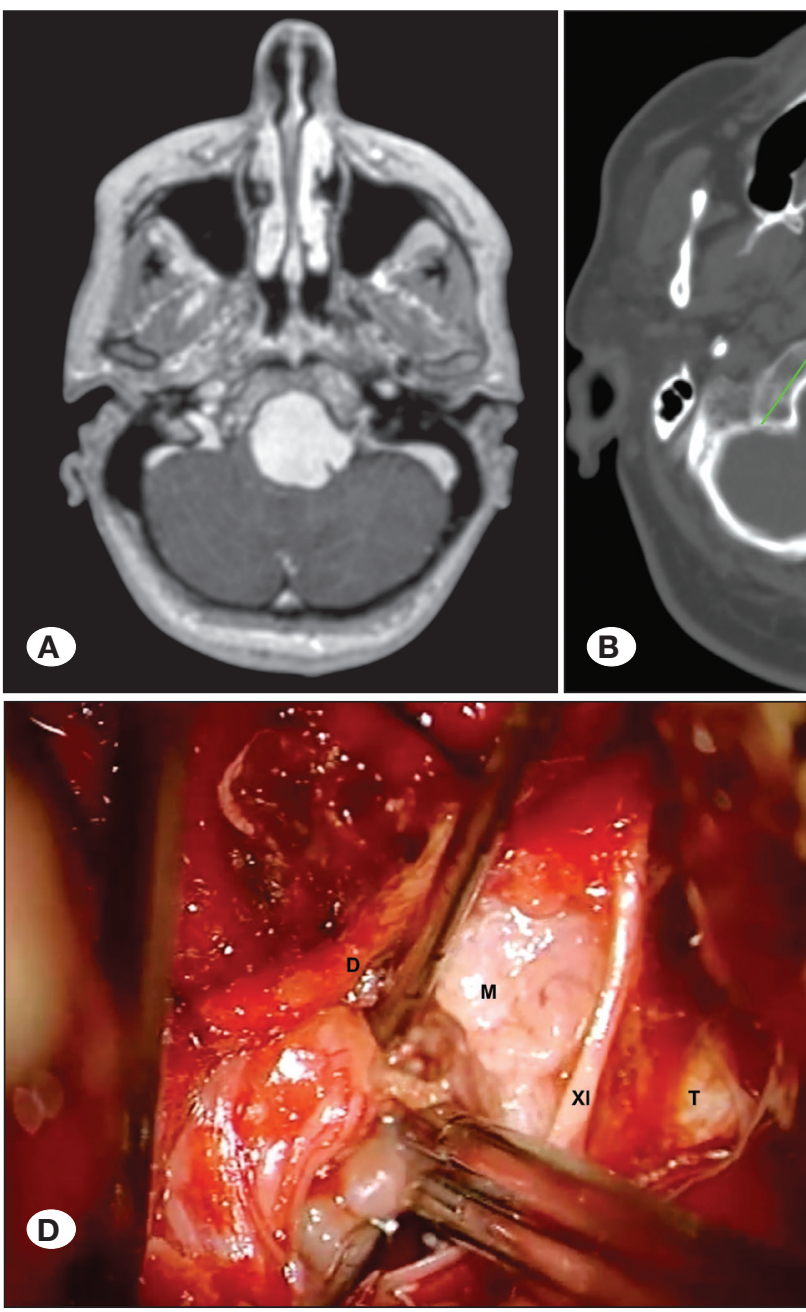
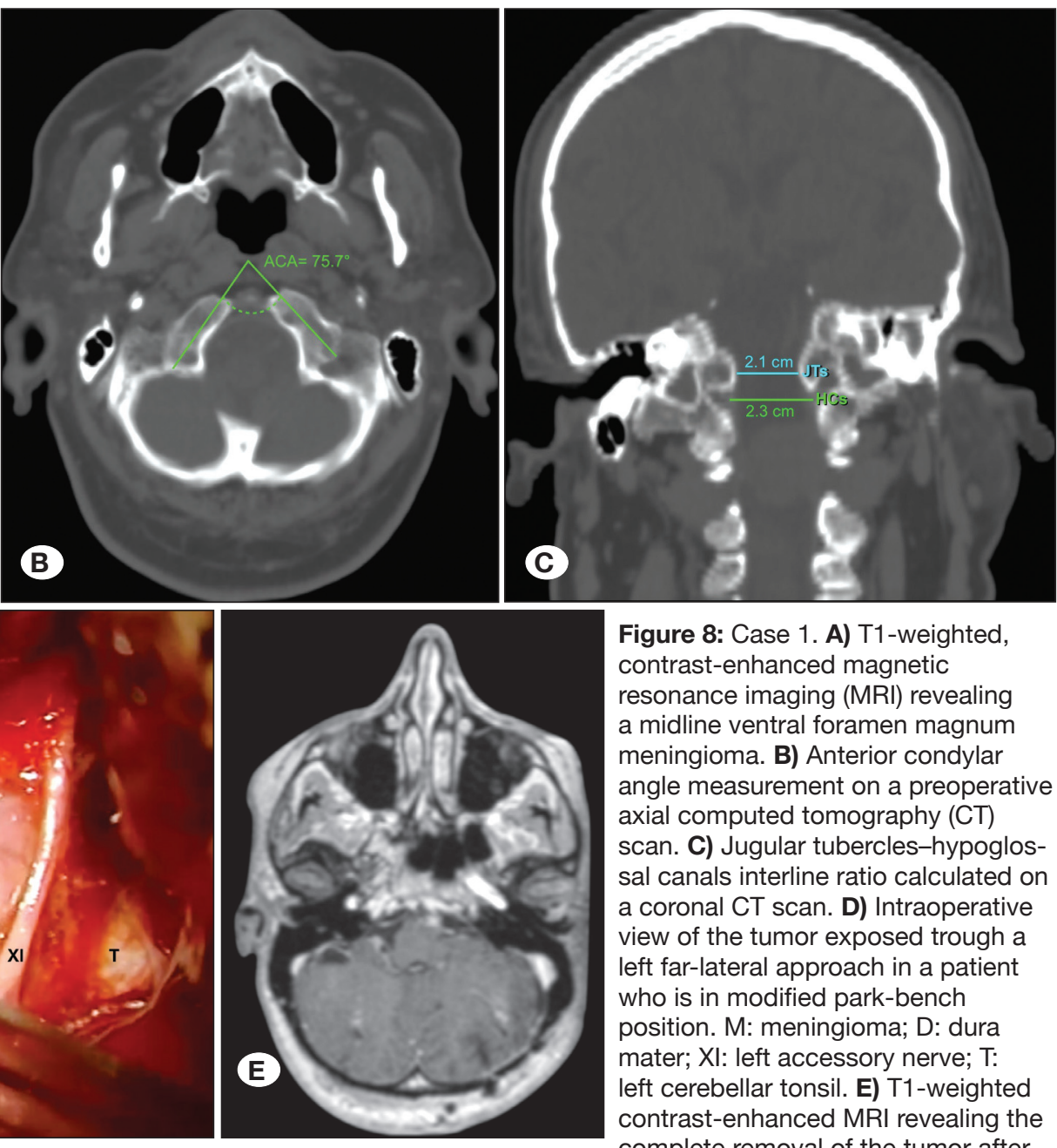

Figure 8: Case 1. A) T1-weighted, contrast-enhanced magnetic resonance imaging (MRI) revealing a midline ventral foramen magnum meningioma. B) Anterior condylar angle measurement on a preoperative axial computed tomography (CT) scan. C) Jugular tubercles-hypoglossal canals interline ratio calculated on a coronal CT scan. D) Intraoperative view of the tumor exposed trough a left far-lateral approach in a patient who is in modified park-bench position. M: meningioma; D: dura mater; XI: left accessory nerve; T: left cerebellar tonsil. E) T1-weighted contrast-enhanced MRI revealing the complete removal of the tumor after 3 months.
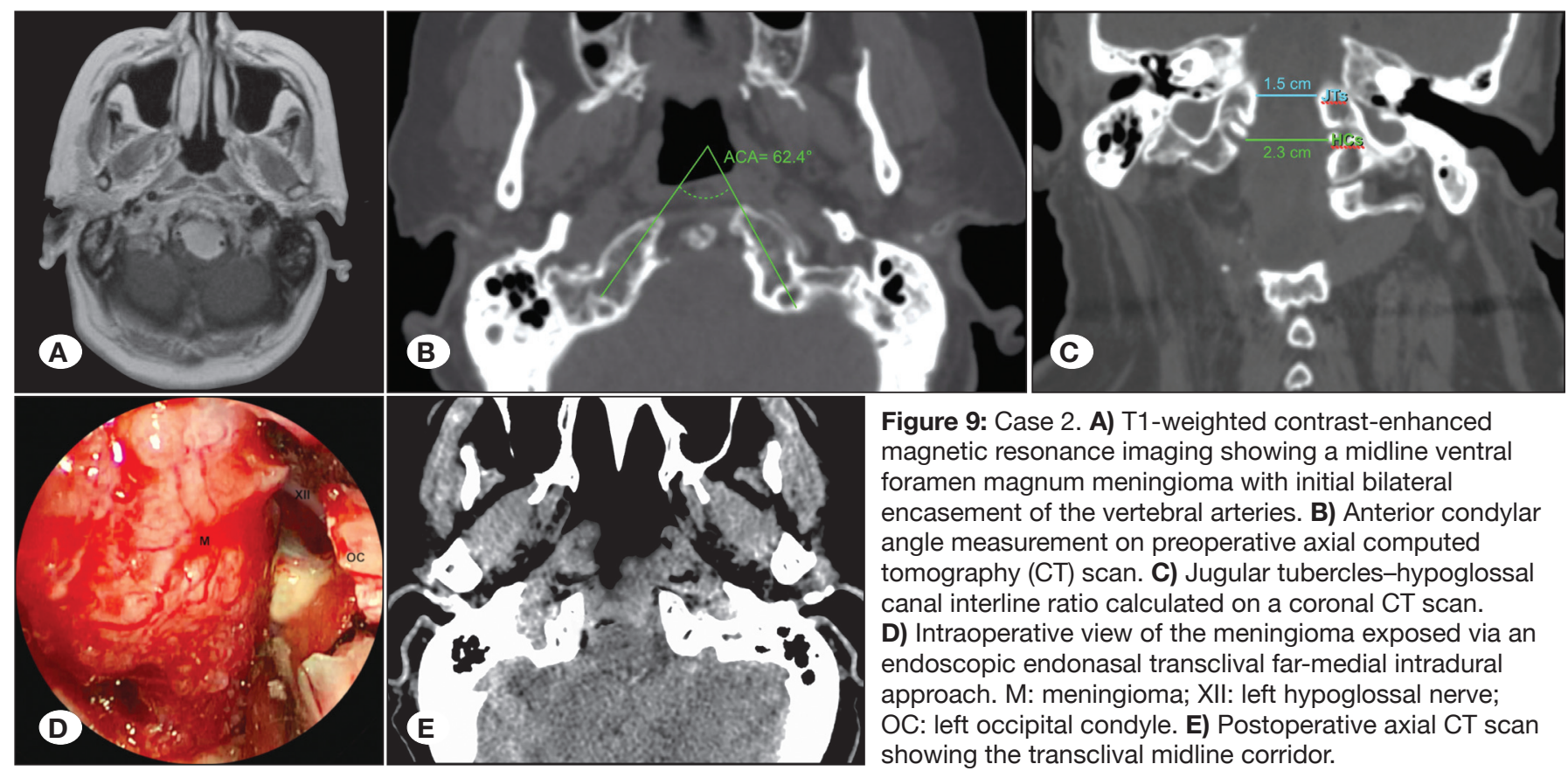

Figure 9: Case 2. A) T1-weighted contrast-enhanced magnetic resonance imaging showing a midline ventral foramen magnum meningioma with initial bilateral encasement of the vertebral arteries. B) Anterior condylar angle measurement on preoperative axial computed tomography (CT) scan. C) Jugular tubercles-hypoglossal canal interline ratio calculated on a coronal CT scan. D) Intraoperative view of the meningioma exposed via an endoscopic endonasal transclival far-medial intradural approach. M: meningioma; XII: left hypoglossal nerve; OC: left occipital condyle. E) Postoperative axial CT scan showing the transclival midline corridor. 
often cause the need for a partial anterior condylectomy with all the related biomechanical consequences. In these cases, a posterolateral intradural approach could be recommended because it may be simpler and less invasive from both an anatomical and biomechanical standpoint. Conversely, an anterior route may be advantageous in cases of narrower ACA and SICA (Figure 10A-D). Naderi et al. have reported a minor average SICA $\left(59.3^{\circ} \pm 13.6\right.$ vs. $\left.69.8 \pm 11\right)$, despite its association with high variability in this study (35). This difference may be due to the fact that they considered the SICA as the angle formed by the intersection between two converging lines traced at the midportion of each condyle, which is different from the present study, in which SICA has been calculated based on the midline intersection of the longest axes of the condyles.

Regarding the JT, equally wide variability was identified from the present data about its prominence within the FM area. Mintelis et al. have reported that the average length, width, and thickness of the JT were $16.5,11.5$, and $0.61 \mathrm{~mm}$, respectively (32). However, these measurements were challenging to obtain directly from CT scans during preoperative planning. That is the main reason why the indirect measures of JT prominence as JT interline and JT-HC interline ratio have been reported in this study. In daily clinical practice, preoperative evaluation of the relationships between the JT and the vertebrobasilar junction is of utmost importance in planning a posterolateral corridor for a wide range of aneurysms in this area $(8,16,28)$. The same concept is also applicable to meningiomas of the lower clivus or petroclival area, particularly if the existence of a central clival depression or an oval-shaped configuration of the FM (FM index $\geq 1.2$ ) lengthens and deepens the surgical corridor (1). A prominent JT obviously makes the far-medial and far-lateral transtubercular approach more complex. Nevertheless, endoscopic extradural drilling of the tubercle is theoretically associated with a lower risk of mechanical and thermal injury to the lower cranial nerves because the bony work is performed frontward to the plane of the nerves. The far-medial approach must be chosen especially when a prominent JT is associated with a narrower ACA and SICA.

In these cases, the need for extradural or intradural drilling of the tubercle adds to that of performing a partial or complete condylectomy to achieve an adequate working angle and ultimately to increase surgical freedom. Our results indicated that a JT-HC interline ratio significantly $<0.8$ can predict a high degree of obstruction in the surgical corridor in the far-lateral approach due to the prominence of the tubercle itself (Figure $11 \mathrm{~A}-\mathrm{D})$.
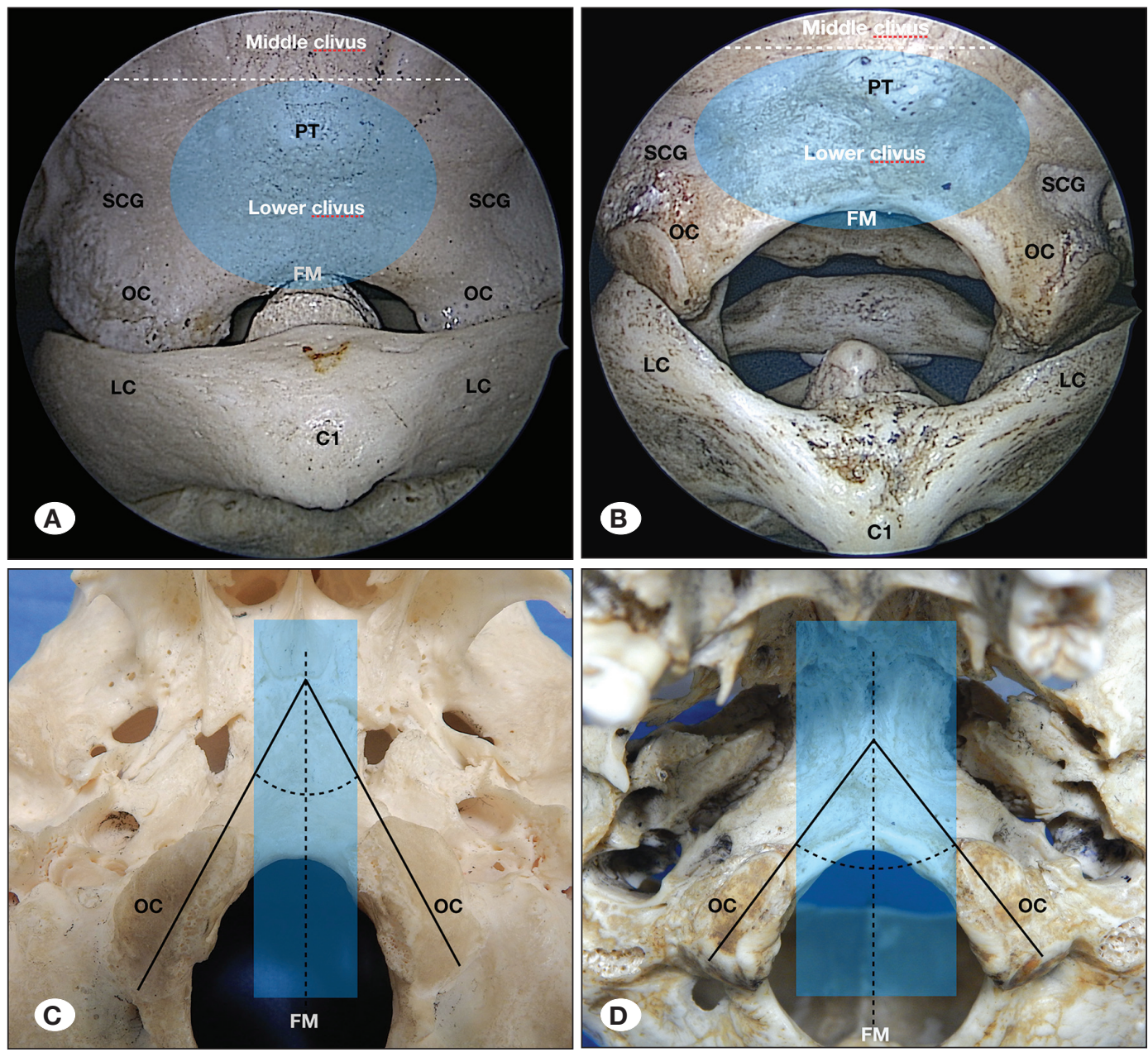

Figure 10: A) Endoscopic endonasal midline view of the foramen magnum region in a skull with a narrow anterior intercondylar distance and a narrow sagittal intercondylar angle (C). B) Same endoscopic view of a skull with a wider anterior intercondylar distance and a wider sagittal intercondylar angle (D).

OC: occipital condyle; LC: lateral condyle; FM: foramen magnum; D: dens of the axis; C1: atlas; PT: pharyngeal tubercle; AICD: anterior intercondylar distance; SCG: supracondylar groove.

The dotted line in figure $A$ and $C$ the inferior clival line and marks the limits between the middle and lower clivus. 

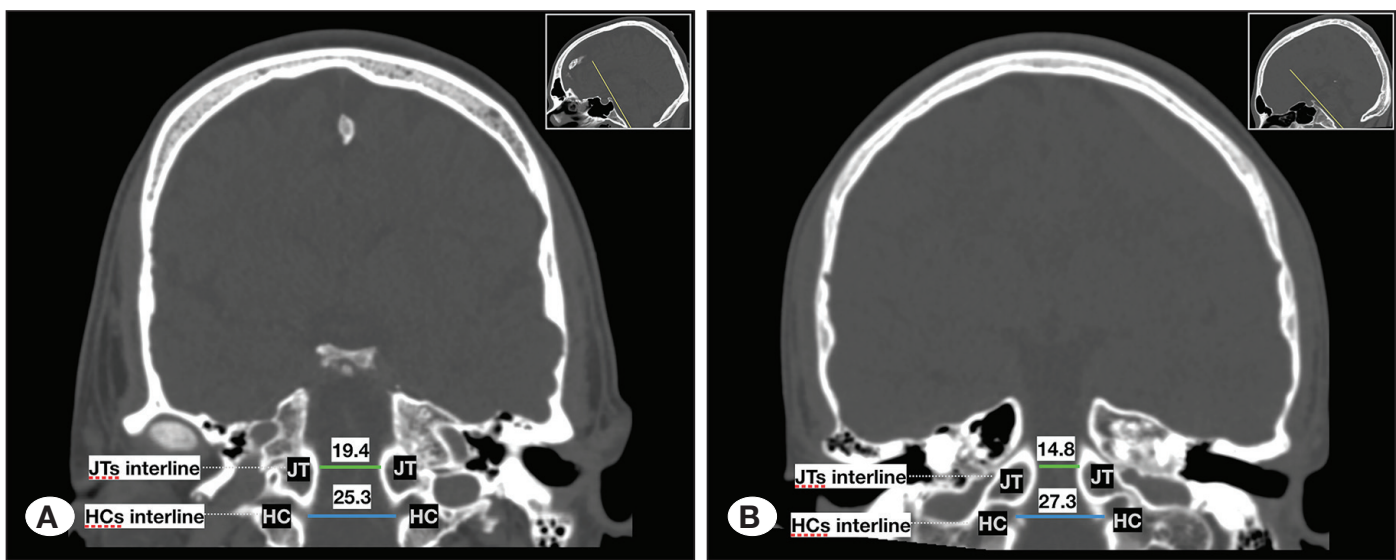

Figure 11: A) Bone window coronal computed tomography (CT) scan of a patient with a jugular tubercles-hypoglossal canal interline (JT-HC) ratio of 0.7 compared with that of another patient with a JT-HC interline ratio of 0.5 (B). The squared areas on the upper right-hand side of both images report
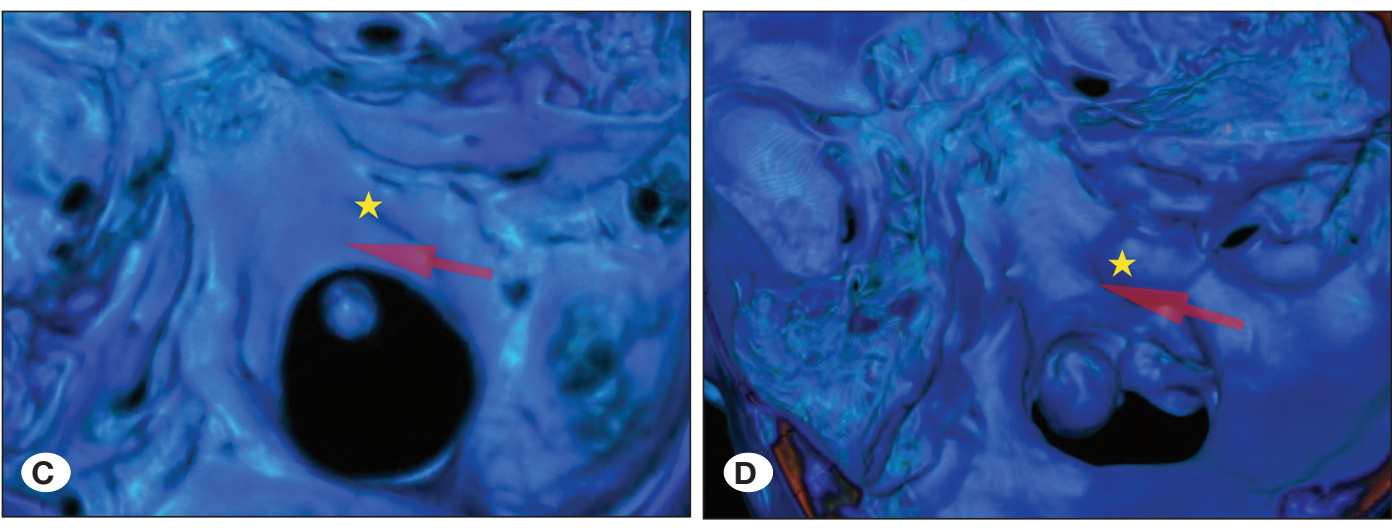
the sagittal CT scans of the same patients also showing the gantry tilt (yellow line) that was set parallel to the clivus. (C-D) 3D rendered CT scan of patients (a) and (b), respectively. The yellow star marks a flat (c) and prominent (d) JT, whereas the red arrow indicates the line of sight of the far-lateral approach. JT: jugular tubercle; HC: hypoglossal canal.

As far as the clivus is concerned, its middle and lower third length were lower in the present study compared with data obtained by Funaki and colleagues, and this difference may be attributed to the limited number of skulls that were analyzed, resulting in reduced dimensional variability (15).

\section{Limitations}

Although it was established that the skulls were not pediatric, no further information about the dry skulls in terms of age, sex, and ethnicity is available, and such factors may cause bias. Nevertheless, a Gaussian distribution has been considered based on the sample size, which is non-negligible.

A further source of bias should be assumed for what has affected the presumed lesser accuracy of the measurements performed using the means of the digital tools of the imaging workstation, compared with the direct measurements performed with the caliper.

Further clinical studies must be conducted to validate the reported data.

\section{CONCLUSION}

A comprehensive case-by-case morphometric analysis of the FM region is important not only for planning and using individualized and safe anterior and posterolateral approaches to ventral intradural lesions but also for identifying all the advantages of a specific corridor as much as possible while minimizing the risk of complications.
Preoperative evaluation of the ACA, SICA, and JT-HC interline ratio, along with other fundamental lesion-related aspects, may be a discriminating factor in choosing between an anterior versus posterolateral surgical route.

In an ACA and SICA narrower than $35^{\circ}$ and $70^{\circ}$, respectively, an anterior approach may be more advantageous. Conversely, a posterolateral corridor must be chosen in cases of wider ACA and SICA, particularly if they are associated with a JT$\mathrm{HC}$ interline ratio $\geq 0.8$.

\section{ACKNOWLEDGMENTS}

We want to thank Eng. Giorgia Di Giusto for her valuable technical support in the data collection and analysis.

\section{REFERENCES}

1. Abdel Aziz KM, Sanan A, van Loveren HR, Tew JM Jr, Keller JT, Pensak ML: Petroclival meningiomas: Predictive parameters for transpetrosal approaches. Neurosurgery 47:139-150; discussion 150-152, 2000

2. Al-Mefty O, Borba LA, Aoki N, Angtuaco E, Pait TG: The transcondylar approach to extradural nonneoplastic lesions of the craniovertebral junction. J Neurosurg 84:1-6, 1996

3. Babu RP, Sekhar LN, Wright DC: Extreme lateral transcondylar approach: Technical improvements and lessons learned. J Neurosurg 81:49-59, 1994 
4. Beer-Furlan A, Vellutini EA, Balsalobre L, Stamm AC: Endoscopic endonasal approach to ventral posterior fossa meningiomas: From case selection to surgical management. Neurosurg Clin N Am 26:413-426, 2015

5. Bozbuga M, Ozturk A, Bayraktar B, Ari Z, Sahinoglu K, Polat G, Gurel I: Surgical anatomy and morphometric analysis of the occipital condyles and foramen magnum. Okajimas Folia Anat Jpn 75(6):329-334, 1999

6. Catalina-Herrera CJ: Study of the anatomic metric values of the foramen magnum and its relation to sex. Acta Anat (Basel) 130:344-347, 1987

7. Choi D, Crockard HA: Evolution of transoral surgery: Three decades of change in patients, pathologies, and indications. Neurosurgery 73:296-303; discussion 294-303, 2013

8. Ciappetta P, Occhiogrosso G, Luzzi S, D’Urso PI, Garribba AP: Jugular tubercle and vertebral artery/posterior inferior cerebellar artery anatomic relationship: A 3-dimensional angiography computed tomography anthropometric study. Neurosurgery 64:429-436; discussion: 436, 2009

9. Cirpan S, Yonguc GN, Mas NG, Aksu F, Orhan Magden A: Morphological and morphometric analysis of foramen magnum: An anatomical aspect. J Craniofac Surg 27:15761578, 2016

10. Crockard HA, Sen CN: The transoral approach for the management of intradural lesions at the craniovertebral junction: Review of 7 cases. Neurosurgery 28:88-97; discussion 97-98, 1991

11. de Oliveira E, Rhoton AL Jr, Peace D: Microsurgical anatomy of the region of the foramen magnum. Surg Neurol 24:293352,1985

12. Erickson N, Siu A, Sherman JH, Gragnaniello C, Singh A, Litvack Z: Endoscopic transnasal transclival approach to a pontine cavernoma with associated developmental venous anomaly. World Neurosurg 118:212-218, 2018

13. Fernandez-Miranda JC, Morera VA, Snyderman $\mathrm{CH}$, Gardner $P$ : Endoscopic endonasal transclival approach to the jugular tubercle. Neurosurgery 71:146-158; discussion: 158-159, 2012

14. Forbes JA, D'Herbemont S, Lehner KR, Pineda Martinez D, Navarro-Chavez IP, Mendez Rosito D, Schwartz TH: Feasibility of endoscopic endonasal approach for clip application of cerebral aneurysms: A systematic review. J Neurosurg Sci 62:650-657, 2018

15. Funaki T, Matsushima T, Peris-Celda M, Valentine RJ, Joo W, Rhoton AL Jr: Focal transnasal approach to the upper, middle, and lower clivus. Neurosurgery 73:ons155-190; discussion ons 190-191, 2013

16. Gallieni M, Del Maestro M, Luzzi S, Trovarelli D, Ricci A, Galzio $\mathrm{R}$ : Endoscope-assisted microneurosurgery for intracranial aneurysms: Operative technique, reliability, and feasibility based on 14 years of personal experience. Acta Neurochir Suppl 129:19-24, 2018

17. George B, Lot G: Foramen magnum meningiomas: A review from personal experience of 37 cases and from a cooperative study of 106 cases. Neurosurgery Quarterly 5:149-167, 1995
18. Gomez-Amador JL, Ortega-Porcayo LA, Palacios-Ortiz IJ, Perdomo-Pantoja A, Nares-Lopez FE, Vega-Alarcon A: Endoscopic endonasal transclival resection of a ventral pontine cavernous malformation: Technical case report. $J$ Neurosurg 127:553-558, 2017

19. Gunaldi O, Kina H, Tanriverdi O, Erdogan U, Postalci LS: Endoscopic endonasal transclival resection of the upper clival meningioma. Turk Neurosurg 28:505-509, 2018

20. Heros RC: Lateral suboccipital approach for vertebral and vertebrobasilar artery lesions. J Neurosurg 64:559-562, 1986

21. Karam YR, Menezes AH, Traynelis VC: Posterolateral approaches to the craniovertebral junction. Neurosurgery 66:135-140, 2010

22. Kassam A, Snyderman CH, Mintz A, Gardner P, Carrau RL: Expanded endonasal approach: The rostrocaudal axis. Part II. Posterior clinoids to the foramen magnum. Neurosurg Focus 19:E4, 2005

23. Khattar N, Koutourousiou M, Chabot JD, Wang EW, CohenGadol AA, Snyderman CH, Fernandez-Miranda JC, Gardner PA: Endoscopic endonasal and transcranial surgery for microsurgical resection of ventral foramen magnum meningiomas: A preliminary experience. Oper Neurosurg (Hagerstown) 14:503-514, 2018

24. Lang J: Skull Base and Related Structures. An Atlas of Clinical Anatomy. Stuttgart: Schattauer, 1995

25. Lanzino G, Paolini S, Spetzler RF: Far-lateral approach to the craniocervical junction. Neurosurgery 57:367-371; discussion 367-371, 2005

26. Lemos-Rodriguez AM, Sreenath $S$, Unnithan $A$, Doan $V$, Recinos PF, Zanation A, Sasaki-Adams D: A new window for the treatment of posterior cerebral artery, superior cerebellar artery, and basilar apex aneurysm: The expanded endoscopic endonasal approach. J Neurol Surg B Skull Base 77:308-313, 2016

27. Linsler S, Oertel J: Endoscopic endonasal transclival resection of a brainstem cavernoma: A detailed account of our technique and comparison with the literature. World Neurosurg 84:20642071, 2015

28. Luzzi S, Gallieni M, Del Maestro M, Trovarelli D, Ricci A, Galzio R: Giant and very large intracranial aneurysms: Surgical strategies and special issues. Acta Neurochir Suppl 129:2531,2018

29. Lyrtzis C, Piagkou M, Gkioka A, Anastasopoulos N, Apostolidis S, Natsis K: Foramen magnum, occipital condyles and hypoglossal canals morphometry: Anatomical study with clinical implications. Folia Morphol (Warsz) 76:446-457, 2017

30. Matsushima T, Natori Y, Katsuta T, Ikezaki K, Fukui M, Rhoton AL: Microsurgical anatomy for lateral approaches to the foramen magnum with special reference to transcondylar fossa (supracondylar transjugular tubercle) approach. Skul Base Surg 8:119-125, 1998

31. Menezes AH: Surgical approaches: Postoperative care and complications "posterolateral-far lateral transcondylar approach to the ventral foramen magnum and upper cervical spinal canal". Childs Nerv Syst 24:1203-1207, 2008 
32. Mintelis A, Sameshima T, Bulsara KR, Gray L, Friedman AH, Fukushima T: Jugular tubercle: Morphometric analysis and surgical significance. J Neurosurg 105:753-757, 2006

33. Morera VA, Fernandez-Miranda JC, Prevedello DM, Madhok R, Barges-Coll J, Gardner P, Carrau R, Snyderman $\mathrm{CH}$, Rhoton AL Jr, Kassam AB: "Far-medial" expanded endonasal approach to the inferior third of the clivus: The transcondylar and transjugular tubercle approaches. Neurosurgery 66:211219; discussion 219-220, 2010

34. Muthukumar N, Swaminathan R, Venkatesh G, Bhanumathy SP: A morphometric analysis of the foramen magnum region as it relates to the transcondylar approach. Acta Neurochir (Wien) 147:889-895, 2005

35. Naderi S, Korman E, Citak G, Guvencer M, Arman C, Senoglu $M$, Tetik S, Arda MN: Morphometric analysis of human occipital condyle. Clin Neurol Neurosurg 107:191-199, 2005

36. Nayak NR, Thawani JP, Sanborn MR, Storm PB, Lee JY: Endoscopic approaches to brainstem cavernous malformations: Case series and review of the literature. Surg Neurol Int 6:68, 2015

37. Olivier G: Biometry of the human occipital bone. J Anat 120:507-518, 1975

38. Ozer MA, Celik S, Govsa F, Ulusoy MO: Anatomical determination of a safe entry point for occipital condyle screw using three-dimensional landmarks. Eur Spine J 20:15101517, 2011

39. Radinsky L: Relative brain size: A new measure. Science 155:836-838, 1967

40. Rhoton AL Jr: The foramen magnum. Neurosurgery 47:S155193, 2000

41. Salas E, Sekhar LN, Ziyal IM, Caputy AJ, Wright DC: Variations of the extreme-lateral craniocervical approach: Anatomical study and clinical analysis of 69 patients. J Neurosurg 90:206219, 1999

42. Samii M, Tatagiba M: Experience with 36 surgical cases of petroclival meningiomas. Acta Neurochir (Wien) 118:27-32, 1992

43. Samii M, Tatagiba M, Carvalho GA: Resection of large petroclival meningiomas by the simple retrosigmoid route. $J$ Clin Neurosci 6:27-30, 1999

44. Sanborn MR, Kramarz MJ, Storm PB, Adappa ND, Palmer JN, Lee JY: Endoscopic, endonasal, transclival resection of a pontine cavernoma: Case report. Neurosurgery 71:198-203, 2012
45. Sanmillan JL, Lawton MT, Rincon-Torroella J, El-Sayed IH, Zhang X, Meybodi AT, Gabarros A, Benet A: Assessment of the endoscopic endonasal transclival approach for surgical clipping of anterior pontine anterior-inferior cerebellar artery aneurysms. World Neurosurg 89:368-375, 2016

46. Schwartz TH, Fraser JF, Brown S, Tabaee A, Kacker A, Anand VK: Endoscopic cranial base surgery: Classification of operative approaches. Neurosurgery 62:991-1002; discussion 1002-1005, 2008

47. Sen CN, Sekhar LN: An extreme lateral approach to intradur ions of the cervical spine and foramen magnum. Neurosurgery 27:197-204, 1990

48. Somanna S, Babu RA, Srinivas D, Narasinga Rao KV, Vazhayil V: Extended endoscopic endonasal transclival clipping of posterior circulation aneurysms-an alternative to the transcranial approach. Acta Neurochir (Wien) 157:2077-2085, 2015

49. Szentirmai O, Hong Y, Mascarenhas L, Salek AA, Stieg PE, Anand VK, Cohen-Gadol AA, Schwartz TH: Endoscopic endonasal clip ligation of cerebral aneurysms: An anatomical feasibility study and future directions. J Neurosurg 124:463468, 2016

50. Teixeira WR: Sex identification utilizing the size of the foramen magnum. Am J Forensic Med Pathol 3:203-206, 1982

51. Vellutini Ede A, Balsalobre L, Hermann DR, Stamm AC: The endoscopic endonasal approach for extradural and intradural clivus lesions. World Neurosurg 82:S106-115, 2014

52. von Elm E, Altman DG, Egger M, Pocock SJ, Gøtzsche PC, Vandenbroucke JP: The Strengthening the reporting of observational studies in epidemiology (STROBE) statement: Guidelines for reporting observational studies. The Lancet 370:1453-1457, 2007

53. Wang WH, Abhinav K, Wang E, Snyderman C, Gardner PA, Fernandez-Miranda JC: Endoscopic endonasal transclival transcondylar approach for foramen magnum meningiomas: surgical anatomy and technical note. Oper Neurosurg (Hagerstown) 12:153-162, 2016

54. Wen HT, Rhoton AL Jr, Katsuta T, de Oliveira E: Microsurgical anatomy of the transcondylar, supracondylar, and paracondylar extensions of the far-lateral approach. J Neurosurg 87:555585,1997 